\title{
MELHORIA DO PROCESSO DE PROSPECÇÃO DE CLIENTES EM UMA EMPRESA JÚNIOR NUMA UNIVERSIDADE PARTICULAR DA BAIXADA FLUMINENSE
}

Anderson de Oliveira Linhares (UNIGRANRIO); andersonlinhares@ unigranrio.br Allan Chaves dos Santos (UNIGRANRIO); allan.upc@gmail.com Rubens Aguiar Walker (UNIGRANRIO); rubens.walker@unigranrio.edu.br Maria Cristina Ravagnani Gonçalvez (UNIGRANRIO); crisravagnani@ unigranrio.edu.br Marcos dos Santos (UNIGRANRIO); marcosdossantos_doutorado_uff@yahoo.com.br

\section{Resumo}

Este trabalho tem a finalidade de apresentar a estruturação dos processos de negócios de uma empresa de consultoria júnior aplicando a prática de gerenciamento de projetos em seu habito organizacional. Para compreender a estruturação de processos, foram realizadas pesquisas bibliográficas para demostrar a importância do estudo de caso.

Com aplicação do modelo de mapeamento de processos e com auxílio de ferramentas para modelagem da organização, buscou-se identificar o problema, acompanhar as atividades, propor mudanças, remodelar e corrigir para que as práticas e os processos se aprimorem continuamente.

Identificar os problemas internos da organização relacionado com o planejamento, gestão e controle dos processos importantes estrategicamente para atingir a competividade da empresa de consultoria. Além disso, visa ajudar os futuros consultores a auxiliar no desenvolvimento da padronização dos processos, conhecimento da maturidade e aperfeiçoamento do seu negócio.

O presente trabalho visa demonstrar as propostas de melhorias internas da empresa através de um estudo de caso aplicado em uma consultoria júnior, focando na reestruturação da empresa, priorização do processo e identificação do nível de maturidade e o setor menos desenvolvido em relação ao cenário ideal pelos próprios membros da organização

Palavras-Chaves: Mapeamento de processos, consultoria júnior, matriz de Priorização, Maturidade Empresarial 


\section{Introdução}

Com o avanço tecnológico as organizações tiveram que se enquadrar com um novo mercado extremamente mais competitivo para enfrentar desafios desconhecidos. Nesse cenário o consultor tem a expertise de auxiliar a gestão de negócios em assumir a posição adequada no mercado na frente da concorrência, assim sendo, atendendo a necessidade do cliente.

Neste trabalho tomamos a perspectiva do cliente como ponto de partida. Assim, será proposto a modelagem dos processos de negócios para uma empresa júnior de consultoria abrangendo todos os processos da empresa desde da prospecção do cliente até a empresa finalizar o projeto, além de harmonizar os objetivos empresariais, recursos, processos e resultado.

Inicialmente desenvolvido nos Estados Unidos e na Europa Ocidental no século XX, a consultoria empresarial era baseada apenas em teorias naquela época, entretanto, enfatizando na resolução de problemas práticos por intermédio de ferramentas e expertise do consultor. Desde o início da década passada, ganhou destaque os serviços de consultoria (DAVENPORT; PRUSAK, 2003).

Durante décadas, os estudiosos têm enfatizado a importância dos serviços profissionais. Tais chamadas vêm em um cenário de serviços de consultorias profissionais ganhando importância como eles agora respondem por uma grande parte da economia (KRULL; SMITH; GE, 2012).

Para Saltorato (2016) o consultor tem como principal característica atender a necessidade do cliente, seja ela geral ou específica, além de acompanhar o processo e dar apoio necessário. O serviço prestado pode ser imparcial ou temporário, dependendo do projeto, prazos de entrega, equipes envolvidas dentre outros aspectos.

\section{Descrição do problema}

A proposta de aplicação realizou-se em uma empresa de Consultoria Empresarial localizada na região da Baixada Fluminense, no Rio de Janeiro. Os dados foram levantados em conjunto com os consultores e, principalmente, com o responsável pelo setor de projetos. A ênfase do foco de uma empresa é a sustentabilidade financeira e ambiental de onde realiza suas atividades. Ademais, a organização não possui uma metodologia de gestão de projetos. Por circunstância do atual cenário, sente-se a necessidade de se analisar algum recurso para melhorar a administração da gestão de projetos e dar uma melhor eficiência em qualidade aos seus projetos. 
Atualmente quando um novo cliente realiza uma análise diagnóstica com a empresa, uma das principais dificuldades é determinar o prazo de entrega, devido que o projeto detém uma quantidade elevada de etapas até o projeto ser concluído.

O problema que ocorre nesta empresa de consultoria júnior, é a falta de uma metodologia de gestão de projetos como base cultural que tem como consequência atrasos na execução de projetos, falta de padronização de processos, falta de indicadores e muitas das vezes as execuções sendo realizada de forma empiricamente o que dificulta muito a melhoria contínua interna da empresa

Na Figura 1 abaixo: É apresentado o Funil de Vendas de janeiro a setembro de 2019 para entender melhor o problema abordado

Figura 1: Funil de Vendas de Janeiro a Setembro de 2019

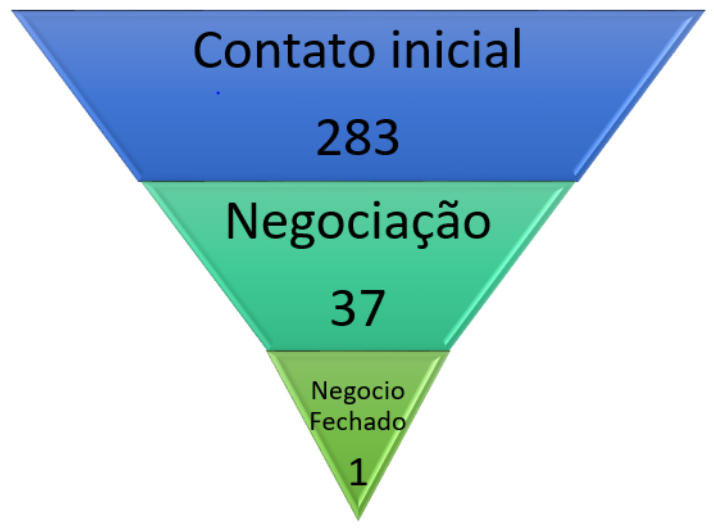

Fonte: Autores (2019)

Conforme a figura 1 demonstra o funil de vendas da empresa que apresentou um nível muito baixo desempenho de negociação em relação as vendas fechadas, com cerca de $2,7 \%$ durante os meses de janeiro a setembro de 2019. Logo, o número de ligações/contato inicial com o cliente é extremamente elevado, devido ser feito por todos os envolvidos da organização. Gerando assim, um retrabalho de 246 ligações na primeira etapa de prospecção de clientes e 36 renegociações na segunda etapa.

\section{Método}

No presente capítulo será abordado todas as definições e os conceitos das ferramentas que será fundamental para atingir o objetivo e auxiliar durante o desdobramento e execução deste trabalho. 


\subsection{Cadeia de Valor}

A cadeia de valor é constituída por um conjunto de atividades primárias e de suporte. Para as principais atividades consistem em logística de entrada, operações, logística de distribuição, marketing, vendas e serviços. As atividades de apoio consistem na infraestrutura de uma empresa, gestão de recursos humanos, desenvolvimento de tecnologia e atividades de elaboração de projetos ou serviços. Cada função na organização deve saber o que acontece com o produto em cada etapa para garantir seu valor está sendo adicionado ao produto (Porter, 1989).

Figura 2: Cadeia de Valor

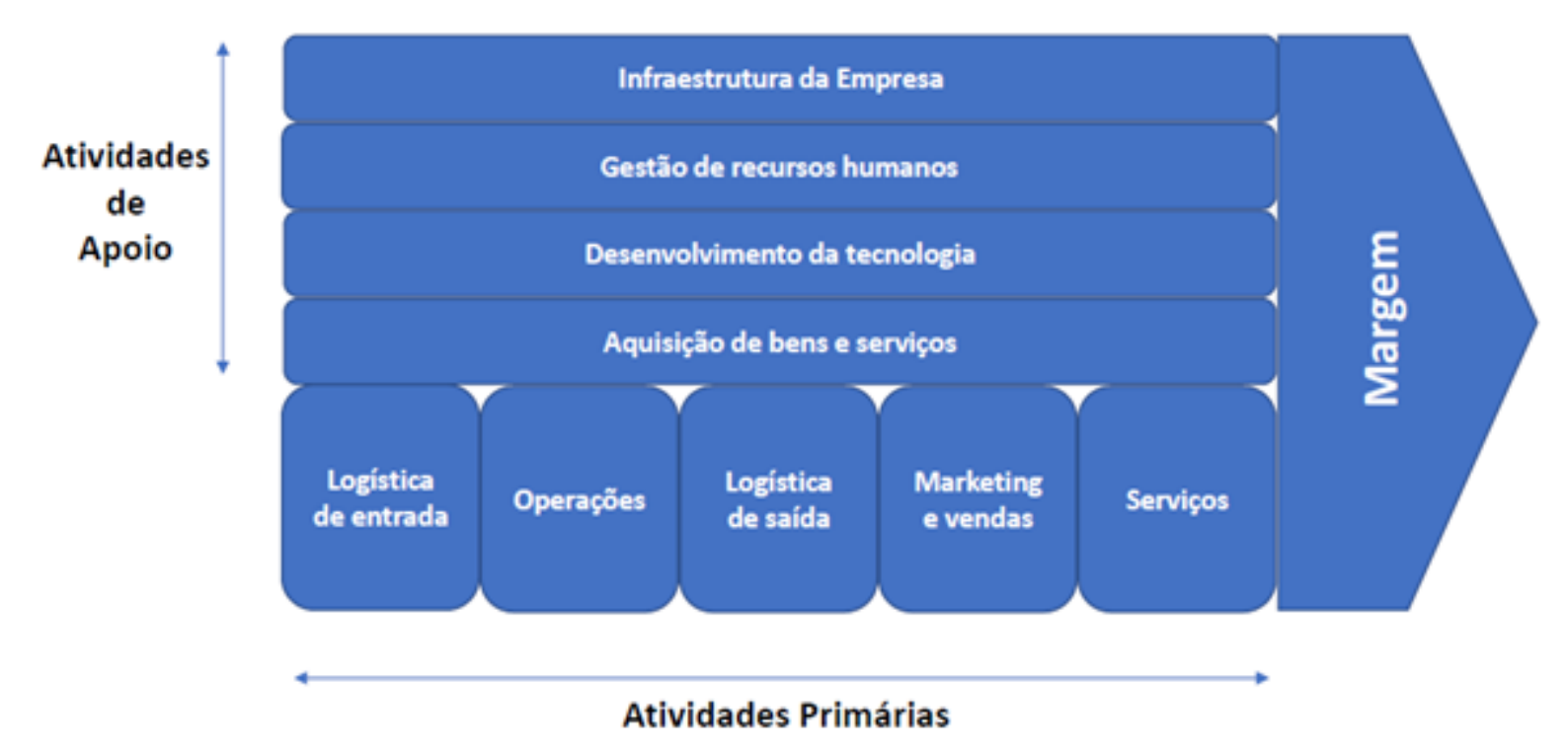

Fonte: Porter (1989)

Pode-se observar em praticamente todas as empresas as atividades primárias.

\subsection{Mapeamento de processos}

Se tratando de uma ferramenta essencial para a gestão e a comunicação dos envolvidos no processo, o mapeamento de processos é capaz ainda de possibilitar a diminuição de custos na prestação de serviços, a diminuição nas falhas de incorporação entre sistemas e aumenta a eficiência e eficácia de desempenho da organização. Ademais é uma ótima ferramenta que garante o melhor entendimento dos processos atuais e apaga ou descomplica aqueles que precisam de mudanças (GOMES, et al., 2015). 
Em relação a análise dos processos, refere-se de uma assistência relacionada ao trabalho realizado e de como é capaz de ser reformulado. Deste modo, a análise dos processos se iniciação com a identificação de uma possível nova oportunidade para o desenvolvimento da maturidade do processo e termina com a implementação de um processo refeito. Posto que, a última fase volta para a primeira, formando, deste modo, um ciclo de melhoria contínua (KRAJEWSKI; RITZMAN; MALHOTRA, 2009).

Figura 3: análise dos processos e suas respectivas etapas

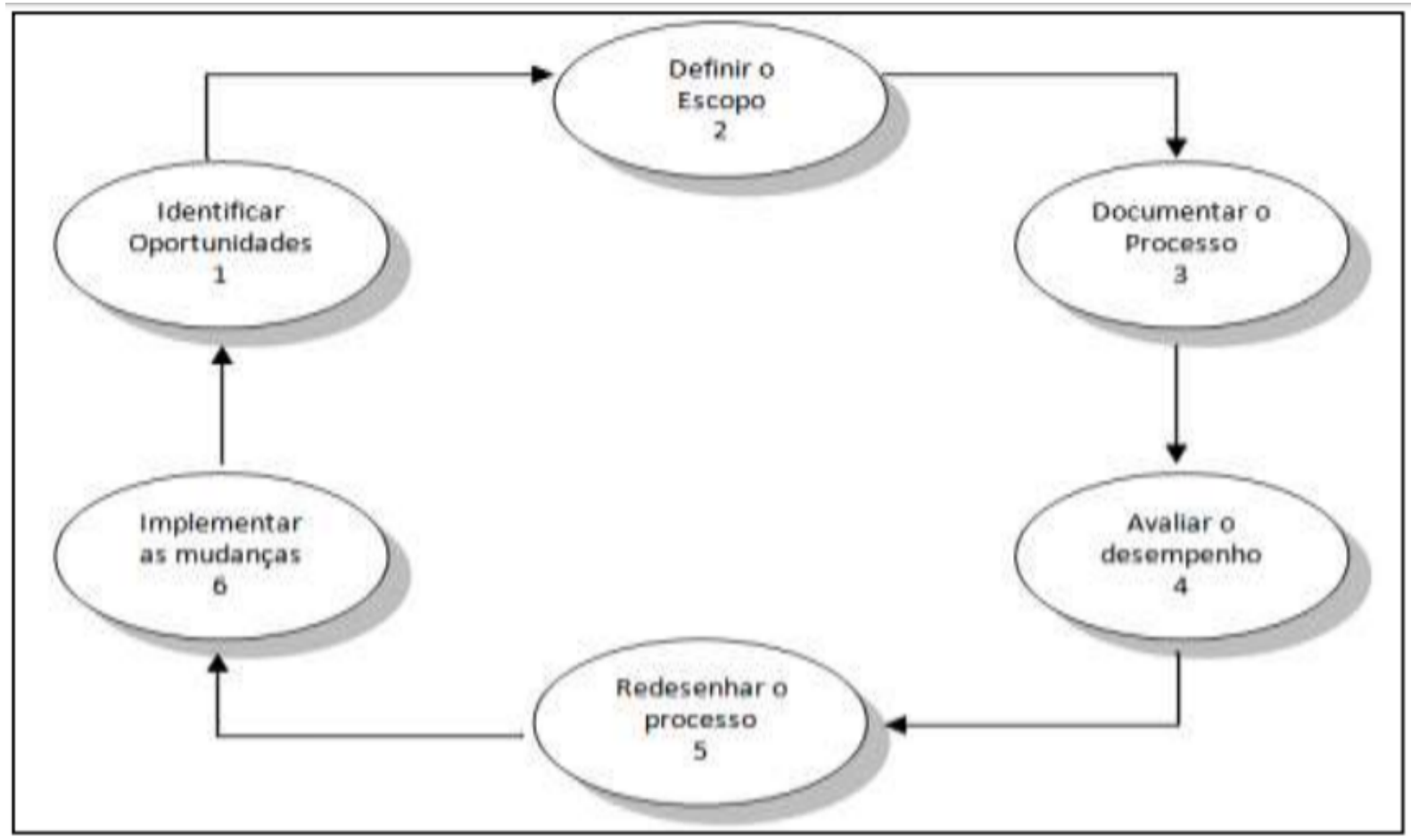

Fonte: Adaptado de Krajewski, Ritzman e Malhotra (2009)

Nesse enquadramento, dentro das empresas, os processos retratam o suporte dos produtos que serão fabricados e isso requer um gerenciamento organizado. Deste modo, Chase, Jacobs e Aquilano (2006); Miyashita e Salomon (2011) a organização que não conter processos que atendem às demandas da mesma, é capaz de ter sua produção reduzida. Assim, entender o funcionamento devido dos processos atesta que as operações aconteçam conforme o planejado.

\subsection{Ferramenta BPMN}

A ferramenta BPMN viabiliza uma descrição objetiva e clara, mas também flexível dos seus processos internos e externos. Ao mesmo tempo permite comunicar aos seus parceiros os 
processos de maneira compreensível para eles. A origem e objetivo principal do BPMN é criar um tipo de modelo e uma notação comum que seja inteligível por qualquer usuário do processo. Ou seja, que todas as partes envolvidas no processo usem a mesma linguagem para se comunicar (SILVER, 2009).

A Figura 4 a seguir demonstra um exemplo de mapeamento de macroprocesso com processo utilizando o BPMN:

Figura 4: Exemplo de mapeamento de macroprocesso com processo utilizando o BPMN

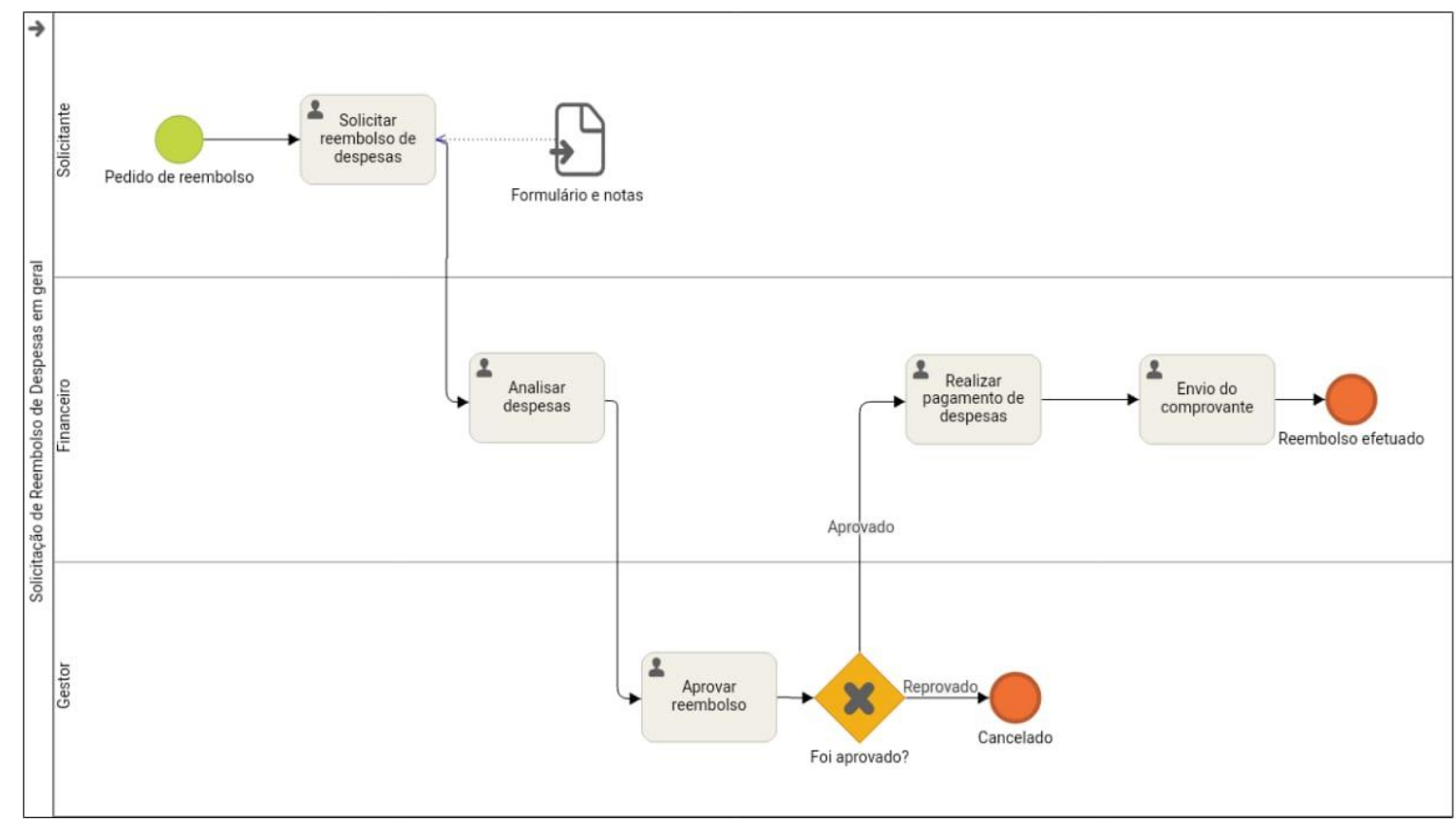

Fonte: HEFLO (2019)

Conforme a Figura 4 nota-se que o mapeamento organiza os processos e demonstra o início do processo até o final do mesmo. Neste exemplo demonstra o processo para solicitação de reembolso de despesas em geral, retratando desde a solicitação de reembolso até a efetuação do pagamento.

\subsection{Matriz de priorização}

A matriz de priorização tem como objetivo de reduzir e classificar, de forma racional, o número de componentes a serem implementados. É uma ferramenta auxiliada pela matriz de afinidades, que tem a função de organizar os dados para posteriormente serem ordenados na matriz de priorização. 
A matriz de priorização é uma matriz especialmente construída para ordenar uma lista de itens. É uma ferramenta para tomada de decisão, já que estabelece uma priorização, que pode ou não ser baseada em critérios com pesos definidos.

Figura 5: Matriz de priorização

\begin{tabular}{|c|c|c|c|c|c|}
\hline Macro Processo & Processo & Custo & Frequencia & Automação & Priorização \\
\hline Customer Service & Registro de pedidos & $\begin{array}{ll}0 & 3 \\
\end{array}$ & 3 & +1 & 18 \\
\hline Distribuição & Programação de entregas & ○ & 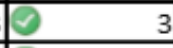 & (1) & 18 \\
\hline Distribuição & Monitoramento de entregas & 8 & (O) & (1) & 18 \\
\hline Distribuição & Controle de devolução & (1) & (1) & 8 & 12 \\
\hline Distribuiç̧ão & Apuração de Performance & (1) & (1) & 1 & 8 \\
\hline Customer Service & Indica prioridade no atendimento & $\varnothing$ & (1) & 8 & 6 \\
\hline Cadastro & Verificação de crédito & $\otimes$ & 0 & $\otimes$ & 3 \\
\hline Cadastro & Cadastra novos clientes & 8 & (2) & (1) & 2 \\
\hline Contas a receber & Cobrança ao cliente & 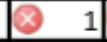 & 1 & 8 & 2 \\
\hline Contas a receber & Negativação do cliente & 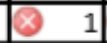 & 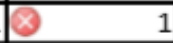 & 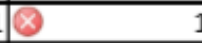 & 1 \\
\hline
\end{tabular}

Fonte: Autores (2019)

A matriz de priorização pode variar diversas formas de ser calculado dependendo da necessidade da empresa. Pode-se observar na Figura 8 que o processo a ser priorizado é o somatório do custo, frequência e automação. Neste caso, existem 3 processos a ser priorizado devido o resultado atingido.

\subsection{Maturidade Empresarial}

A maturidade significa o grau de utilização das boas práticas em gerenciamento de projetos de uma organização e o quanto essa utilização melhora os resultados. Quantos mais madura for uma organização, maior será a taxa de sucesso de seus projetos. Para alcançar a maturidade, existe um esforço contínuo que geralmente leva alguns anos até que os resultados alcançados reflitam uma taxa maior de sucesso nos resultados dos projetos (ALMEIDA; OLIVIERI NETO, 2015).

Os resultados da maturidade de uma organização segundo o modelo OPM3, são demonstrados através de percentuais gerais e percentuais por domínios. Diferentemente dos demais modelos que apresentam o nível de maturidade da organização em escalas numéricas ordinais (ALMEIDA; OLIVIERI NETO, 2015).

Rafael Ávila (2018) descreve a análise empresarial como uma ferramenta de gestão que serve para avaliar a empresa como um todo para aferir quais são os departamentos que tem uma organização e desempenho melhor e aonde existe a necessidade de realização de melhorias. 
Essa análise deve ser imparcial e prática, permitindo dados detalhados que auxiliarão na decisão de prioridades e quais os departamentos necessitam de mais acompanhamento.

Figura 6: Nível de maturidade empresarial

\begin{tabular}{|c|c|c|}
\hline Nivel & Maturidade & $\%$ \\
\hline 1 & $\begin{array}{c}\text { Não existem processos gerenciais aplicados ao negócio e os resultados são } \\
\text { obtidos através de iniciativas desestruturadas. }\end{array}$ & $>\quad 40 \%$ \\
\hline 2 & $\begin{array}{c}\text { Não existem processos gerenciais formais, mas algumas áreas de gestão já } \\
\text { possuem rotinas para gerar os resultados esperados. }\end{array}$ & $>50 \%$ \\
\hline 3 & $\begin{array}{c}\text { Existem processos gerenciais formais, no entanto eles são aplicados de } \\
\text { maneira descoordenada para gerar os resultados esperados. }\end{array}$ & $>\quad 60 \%$ \\
\hline 4 & $\begin{array}{c}\text { Existem processos gerenciais formais e eles são aplicados de maneira } \\
\text { coordenada para atingir os resultados esperados no planejamento tático. }\end{array}$ & $>70 \%$ \\
\hline 5 & $\begin{array}{c}\text { Os processos gerenciais são práticas padrão da empresa. Eles são } \\
\text { monitorados, afetam o negócio e são melhorados continuamente. }\end{array}$ & $>=80 \%$ \\
\hline
\end{tabular}

Fonte: Adaptado de Ávila (2018)

Ávila (2018) divide o resultado do diagnóstico organizacional em 5 níveis de maturidade:

- Nível 1 - De 0\% até $20 \%$ - Não existem processos gerenciais aplicados ao negócio e os resultados são obtidos através de iniciativas desestruturadas.

- Nível 2 - De 20,1\% até 40\% - Não existem processos gerenciais formais, mas algumas áreas de gestão já possuem rotinas para gerar os resultados esperados.

- $\quad$ Nível 3 - De 40,1\% até 60\% - Existem processos gerenciais formais, no entanto eles são aplicados de maneira descoordenada para gerar os resultados esperados.

- $\quad$ Nível 4 - De $60,1 \%$ até $80 \%$ - Existem processos gerenciais formais e eles são aplicados de maneira coordenada para atingir os resultados esperados no planejamento tático.

- $\quad$ Nível 5 - De $80,1 \%$ até $100 \%$ - Parabéns! Os processos gerenciais são práticas padrão da empresa. Eles são monitorados, afetam o negócio e são melhorados continuamente.

\section{Resultados}

Neste capítulo será voltado a análise da cientifica e aplicação das técnicas de padronização de processos na empresa de consultoria júnior, localizada em Duque de Caxias. Analisando, a 
empresa por completo, percebe-se que a divisão das responsabilidades e os processos estão interligados, atravessando por vários departamentos.

O objetivo principal é identificar por meio da priorização o processo mais crítico entre os setores de projetos e operações, marketing, financeiro e recursos humanos. Para isso, será reestruturado o organograma, cadeia de valor, o mapeamento dos macroprocessos da organização e o mapeamento do processo crítico selecionado.

\subsection{Mercado de consultoria}

O Brasil voltou a ter uma expansão na economia o que acarreta a criação de oportunidades para as empresas, é neste momento que o pessoal deve estar preparado para enfrentar um mercado cada vez mais agressivo e que tenham implantado modelos modernos de gestão e de tomada de decisões.

Em 2018 o Movimento empresarial júnior (MEJ, 2019) faturou cerca de 3,2 Milhões de reais com mais de 1600 projetos em diversas áreas de consultoria, acarretando um grande impacto na sociedade e desenvolvimento da interligação do conhecimento teórico das universidades para a prática no meio coorporativo.

\subsection{A empresa}

A empresa de consultoria Júnior, nasceu com a necessidade de levar os alunos para além do aprendizado dentro da sala de aula, servindo como um agente potencializador de promissores jovens universitários que tem a vontade de protagonizar na sociedade da região metropolitana do Rio de Janeiro. Aumentando consideravelmente a confiança, a prática, a rede de contatos, a possibilidade de se ingressar no mercado de trabalho, habilidade na comunicação e habilidade técnica.

A organização estudada neste caso concentra as principais atividades no cliente e quais são as necessidades e expectativas que precisam ser atendidas. Ou seja, analisar as informações recebidas, desenvolver o diagnóstico da realidade da empresa, encontrar soluções para o problema diagnosticado, apresentação de melhorias, acompanhar as etapas para serem concluídas e manter a melhoria contínua dos processos.

O serviço fornecido pela consultoria júnior é a entrega final do projeto desenvolvido pelos seus consultores. Seus projetos são inovadores, com soluções criativas e com qualidade. Os serviços são voltados para área de administração, engenharia de produção e tecnologia da informação, atendendo micro e pequenas empresas da baixada fluminense. 


\subsection{Cadeia de Valor}

Após a padronização, foram analisadas e alinhadas as atividades com o objetivo especificamente de definir a cadeia de valor, conforme apresentado na Figura 7 a seguir.

Figura 7: Cadeia de valor

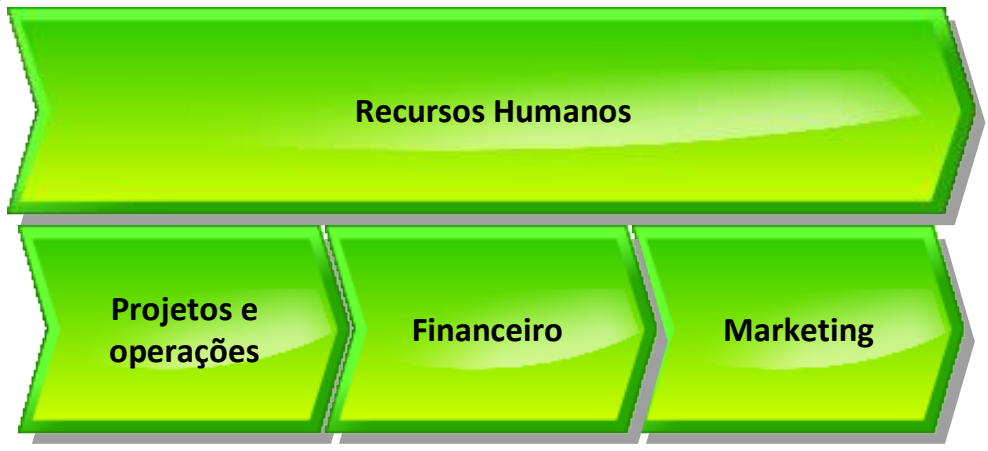

Fonte: Autores (2019)

\subsection{Matriz de Priorização}

Foi elaborado uma lista de processos com intuito de priorizar em relação ao custo por processo, tempo e frequência, de acordo os dados da Figura 8 abaixo:

Figura 8: Priorização

\begin{tabular}{|c|c|c|c|c|c|c|}
\hline Macro Processo & Processo & Custos & Tempo (h) & Frequência & P. Frequência & Priorização \\
\hline Projetos e Operaçöes & Prospecção ativa & 3 & 5 & diária & 1 & 15,000 \\
\hline Projetos e Operações & Identificacão de cliente & 1 & 4 & diária & 1 & 4,000 \\
\hline Marketing & Inteligência comercial & 1 & 5 & semanal & 0,1429 & 0,714 \\
\hline Financeiro & Precificação do projeto & 1 & 3 & semanal & 0,1429 & 0,429 \\
\hline Projetos e Operaçőes & Análise diagnóstica empresarial (reunião) & 4 & 3 & mensal & 0,0333 & 0,400 \\
\hline Projetos e Operaçöes & Criação completa da proposta & 3 & 2 & mensal & 0,0333 & 0,200 \\
\hline Projetos e Operaçőes & Apresentação da proposta & 2 & 2 & mensal & 0,0333 & 0,133 \\
\hline Marketing & Design da proposta & 1 & 2 & mensal & 0,0333 & 0,067 \\
\hline Projetos e Operaçöes & Operação do projeto & 5 & 1 & anual & 0,0027 & 0,014 \\
\hline Projetos e Operaçöes & Apresentação final dos resultados & 2 & 1 & anual & 0,0027 & 0,005 \\
\hline Recursos Humanos & Feedback & 1 & 1 & anual & 0,0027 & 0,003 \\
\hline Financeiro & Primeira parcela efetuado & 1 & 1 & anual & 0,0027 & 0,003 \\
\hline Financeiro & Pagamento efetuado & 1 & 1 & anual & 0,0027 & 0,003 \\
\hline
\end{tabular}

Fonte: Autores (2019)

Podemos notar que o processo mais crítico e que necessita de ação imediata é o setor de projetos e operações, tendo em vista, a dificuldade da empresa em descobrir e captar novos clientes potenciais. Além disso, a prospecção ativa leva muito tempo devido a busca realizada pelas redes sociais e internet, gerando um custo considerável por conta das ligações e gasto de redes móveis do celular da operação. 


\subsection{Mapeamento do processo crítico}

Após a priorização dos processos, foi realizado o mapeamento do processo crítico no departamento de projetos e operações no processo de prospecção ativa de clientes novos. Neste processo, o cliente foi adicionado para facilitar a visualização do fluxo de informações e atividades. Além disso, a prospecção ativa foi designada apenas para os consultores com intuito de diminuir o retrabalho das operações de buscar clientes, apresentar a proposta realizada e contraproposta, a Figura 9 apresenta o mapeamento do processo crítico.

Figura 9: Mapeamento do processo crítico

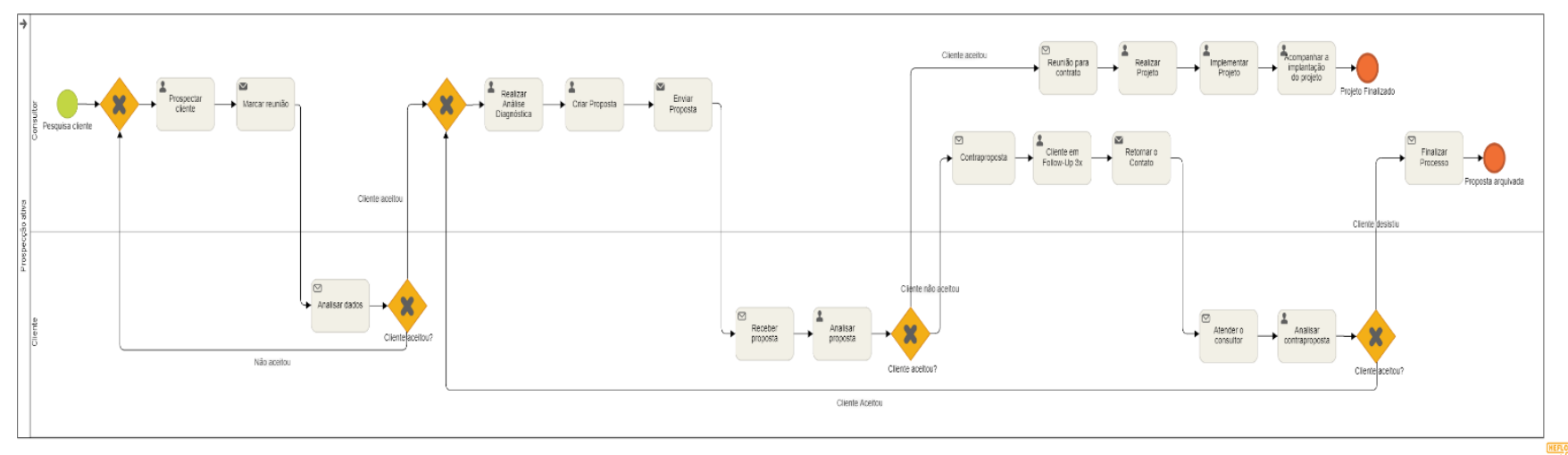

Fonte: Autores (2019)

\subsection{Análise da pesquisa direta comparando com o processo crítico}

Além do método de priorização por meio da análise do organograma, processos e custos, foi realizado uma análise por meio de um método de pesquisa cientifica eficaz, elaborado por um questionário onde cerca de 76,5\% dos membros da empresa responderam esta pesquisa, levando em consideração o setor estratégico, Marketing, Financeiro, Gestão de Pessoas e Projetos. 
Figura 10: Cenário atual

\section{Cenário atual da empresa Nexus Consultoria júnior}

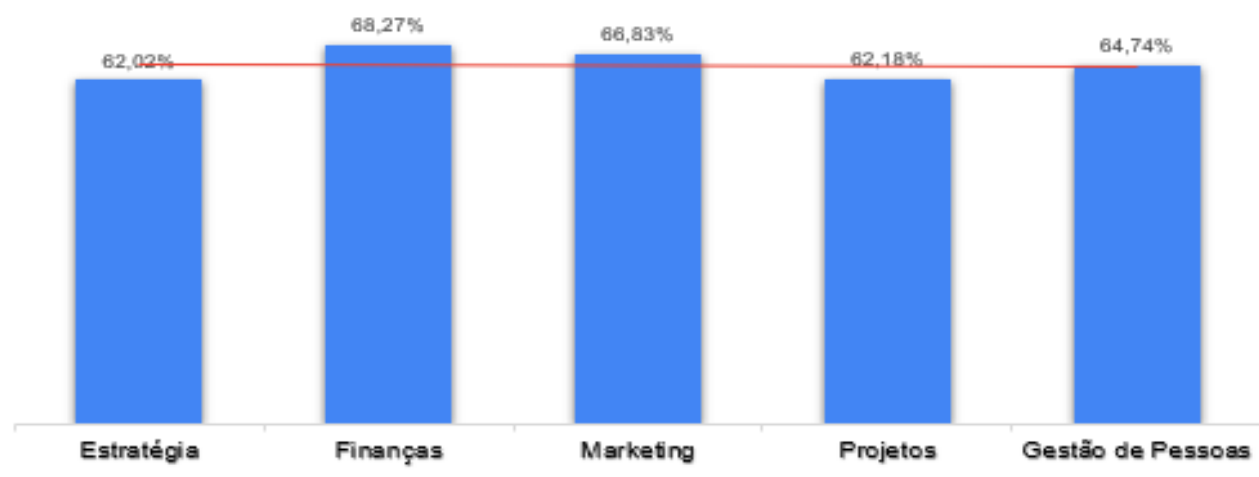

Fonte: Autores (2019)

O questionário desenvolvido por Rafael Ávila (2018) contou com um total de 18 perguntas, com até 4 alternativas, onde as respostas tinham uma variação no resultado de $25 \%$ da pior resposta para $100 \%$ para a melhor resposta, além de avaliar o cenário atual da organização, também foi analisado o cenário ideal com os próprios membros respondendo a cada pergunta, sendo que os resultados também variavam de $25 \%$ a $100 \%$.

Após a coleta de dados, por meio do questionário, realizamos a análise de dados e os dados foram consolidados para transformar em informações para ser realizado propostas de melhoria interna da organização, conforme as Figura 11 e 12 a seguir:

Figura 11: Comparação cenário atual x desejado

\begin{tabular}{|c|c|c|}
\hline Setor & Cenário Atual & Cenário Desejado \\
\hline Estratégia & $62,02 \%$ & $89,90 \%$ \\
\hline Finanças & $68,27 \%$ & $85,10 \%$ \\
\hline Marketing & $66,83 \%$ & $91,83 \%$ \\
\hline Projetos & $62,18 \%$ & $90,38 \%$ \\
\hline Gestão de Pessoas & $64,74 \%$ & $91,03 \%$ \\
\hline
\end{tabular}

Fonte: Autores (2019) 
Figura 12: Pontuação atual x pontuação desejada

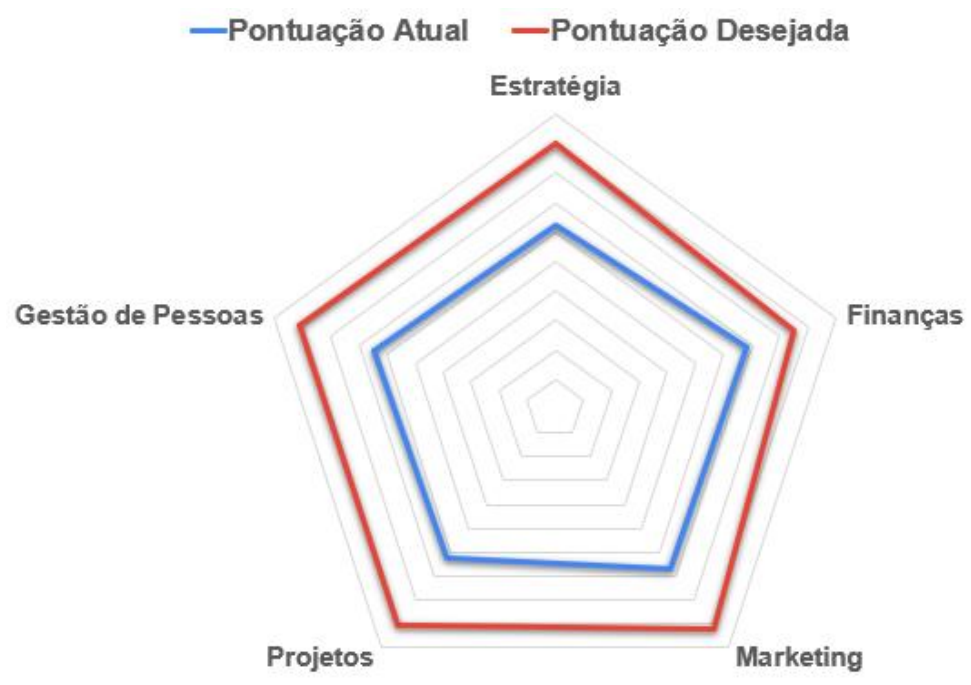

Fonte: Autores (2019)

Após a análise dos dados, foi identificado que o setor de projetos é o setor mais crítico da empresa, devido que a diferença do cenário atual de 62,18\% para o cenário desejado de $90,38 \%$ ser atualmente de $28,20 \%$.

Este resultado mostrou a reafirmação que o processo crítico da empresa Nexus consultoria júnior está atrelado ao setor de Projetos, sendo o setor operacional responsável pelos planos de ações de melhoria interna da organização.

\subsection{Maturidade Empresarial}

Por meio do questionário da análise diagnóstica empresarial, foi analisado e coletado os dados que indicam o nível de maturidade atual da empresa Nexus Consultoria Júnior conforme a figura 16 abaixo:

Figura 13: Nível de maturidade

\begin{tabular}{|c|c|c|c|}
\hline Nível & Maturidade & . & $\%$ \\
\hline 3 & $\begin{array}{l}\text { Existem processos gerenciais formais, no entanto eles são aplicados de } \\
\text { maneira descoordenada para gerar os resultados esperados. }\end{array}$ & $>=$ & $60 \%$ \\
\hline
\end{tabular}

Fonte: Autores (2019)

A consolidação desses dados teve como resultado de $64,81 \%$, sendo considerado no $3^{\circ}$ nível de maturidade empresarial, assim sendo, um nível intermediário que necessita a implementação de melhoria contínua em seus processos internos. 


\section{Discussão dos resultados}

Com base no resultado da análise de priorização do processo crítico e análise da pesquisa, por meio do questionário, pode se dizer que a organização precisa de um plano de ações para cada proposta de melhoria, dentre as propostas de melhorias, destacamos as seguintes: Controle dos processos e qualidade por meio de indicadores, Canais de atendimentos e Controle de prazo.

\section{Conclusão}

O presente estudo de caso teve como objetivo reduzir o retrabalho de prospecção ativa de novos clientes, além de identificar o cenário atual da empresa, proporcionando o maior conhecimento do fluxo de trabalho. Aplicando o mapeamento dos processos, reestruturação da hierarquia da organização, diagnóstico do processo crítico, análise da padronização dos processos e pesquisa de análise diagnóstica para o conhecimento da maturidade que a empresa se encontra atualmente.

Além disso, com o auxílio para reestruturação e análise descritiva da empresa foi possível identificar e priorizar o processo de maior criticidade para o negócio com objetivo de converter leads qualificados em projetos fechados. O mapeamento de processo melhorou o entendimento sobre a empresa e na padronização da prospecção ativa para eliminação do retrabalho.

No primeiro momento foi apresentado o indicador de funil de vendas, demonstrando a necessidade de melhoria de seus resultados devido ao alto índice de não conversão de projetos concluídos.

Para a identificação dos processos mais críticos, foi realizado uma matriz de priorização dos processos com auxílio da análise descritiva da empresa e o organograma reestruturado.

Com base das entrevistas e estudo de campo realizados, foram evidenciados grande parte dos departamentos que não agregavam valor ao cliente. Dessa forma fora proposto designar a responsabilidade dos departamentos de Recursos Humanos e Financeiro para os cargos executivos e assim, reestruturar a hierarquia do organograma atualmente utilizado.

Com o objetivo de identificar os setores que estão diretamente relacionados com o cliente e identificar os setores de apoio que auxiliam as atividades primárias, foi realizado a descrição de cargos e a elaboração da cadeia de valor da organização. 
Ao final do desenvolvimento do mapeamento do processo crítico e matriz de priorização, foram encontrados resultados satisfatórios, possuindo a execução total de todos os objetivos arrolados neste trabalho. Onde foi proposto as melhorias no setor de projetos e operações, visando a redução do retrabalho de processo de prospecção ativa de novos clientes.

Todas estas melhorias referidas acima vão ao encontro os princípios básicos estratégico da Nexus consultoria júnior, que é o aumento da competitividade do negócio, redução do retrabalho e redução de custos operacionais para que a organização entre definitivamente no mercado competitivo de empresa de consultoria júnior do Rio de Janeiro.

\section{Referências}

ALMEIDA, Norberto de Oliveira; OLIVIERI NETO, Rafael. Gestão Profissional do Portfólio de Projetos: Maturidade e Indicadores. Rio de Janeiro: Brasport Livros e Multimídia Ltda, 2015.

CHIAVENATO, Idalberto. Administração de Recursos Humanos: Fundamentos Básicos. 8. ed. Barueri: Manole, 2016. 304 p.

DAVENPORT, Thomas H.; PRUSAK, Laurence. Conhecimento Empresarial: Como as organizações gerenciam o seu capital intelectual. 14. ed. Boston: Elsevier, 2003. 243 p.

GOMES, F. M. M.; FAUSTINO, G.G.; TONANI, M.; PORCINCULA, S.; SOMERA, S.C.; BEICKER, W.; PAZIN-FILHO, A. Mapeamento do fluxo de trabalho: Engenharia Clínica do HCFMRP-USP. Revista de Medicina USP, v. 48, n.1, 41-47, 2015.

KOWALESKI, Z. T.; MAYHEW, B. W.; TEGELER, A. C. The Impact of Consulting Services on Audit Quality: An Experimental Approach. Journal of Accounting Research, v. 56, n. 2, p. 673-711, 2018.

KRAJEWSKI, L.; RITZMAN, L; MALHOTRA, M. Administração de produção e operações. São Paulo: Prentice Hall, 2009.

KRULL, E.; SMITH, P.; GE, G. L. The internationalization of engineering consulting from a strategy tripod perspective. Service Industries Journal, v. 32, n. 7, p. 1097-1119, 2012. PORTER, Michael. Vantagem Competitiva: Criando um desempenho superior. 27. ed. [s.i.]: Campus, 1989.

RAFAEL ÁVILA. Luz Planilhas Empresariais. Como calcular o grau de maturidade com Diagnóstico Organizacional. 2018. Disponível em: <https://blog.luz.vc/como-fazer/comocalcular-o-grau-de-maturidade-com-diagnostico-organizacional/> . Acesso em: 19 out. 2019. 
RUMMLER, Geary A.; BRACHE, Alan P. Melhores desempenhos das empresas: Uma abordagem prática para transformar as organizações através da reengenharia. 2. ed. São Paulo: Marron Books, 1994. 254 p. Tradução de: Kátia Aparecida Roque.

SALTORATO, P. Consultoria Empresarial: Mapeamento de Atividades. 2016.

SILVER, Bruce. BPMN Method \& Style. Cody-Cassidy Press, 2009. 